CAE Working Paper \#06-03

Teacher Truancy in India:

The Role of Culture, Norms and Economic Incentives

by

Kaushik Basu

January 2006 


\title{
Teacher Truancy in India The Role of Culture, Norms and Economic Incentives
}

\author{
Kaushik Basu \\ Professor of Economics and C. Marks Professor of International Studies \\ and Director of the Program on Comparative Economic Development \\ Department of Economics \\ Uris Hall \\ Cornell University \\ Ithaca, New York 14853 \\ U.S.A \\ Fax: 16072552525 \\ Email:kb40@cornell.edu
}

[This is text of the Vera Anstey Memorial Lecture, delivered by the author at the $88^{\text {th }}$ Annual Conference of the Indian Economic Association in Visakhapatnam, on 28 December 2005].

Acknowledgements: I am grateful to the Indian Economic Association for the invitation to deliver the Vera Anstey lecture and to Ashok Mathur for helpful and insightful comments and suggestions following my lecture. 


\section{Teacher Truancy in India The Role of Culture, Norms and Economic Incentives}

\section{Culture}

I shall use the occasion of the Vera Anstey Memorial Lecture to address a neglected theme in the study of economic efficiency and economic progress, namely, the role of culture and social norms. My aim is to first discuss this in general terms and then illustrate it in the context of contemporary India and, in particular, the widely-discussed problem of teacher absenteeism. Given Vera Anstey's unwavering interest in India and the broad inter-disciplinary view that she took of economics, my choice of topic, I hope, is apt.

The laity, unlike professional economists, has long recognized the role of norms and culture. Thus people talk of how certain groups do well economically because they have a 'culture of hard work' or are endowed with the 'Protestant ethic'. It is often maintained that nations or peoples that are characterized by a culture of trust and so have an inclination to honour contracts and not break promises at will are the ones that do better (Fukuyama, 1995). Max Weber, having toured the U.S. in 1904, was impressed by the economic success of the Protestant sects and the impact of this on the whole country; and he put this down to the fact that, as Swedberg (2003, p.232) notes, "the members of the sects were seen as absolutely trustworthy and honest - two qualities that greatly facilitated doing business in a huge country such as the United States."

There are two reasons why economists have ignored these factors. First, by virtue of being non-economic variables they have been perceived as lying beyond the ambit of their expertise. Second, it is often presumed that, even if norms and culture can make a difference, there is not much we can do with this information. The mention of culture easily evokes a sense of fait accompli. Indeed, "a policy for changing culture" has a slightly absurd ring to it.

However, it is arguable that both these presumptions are erroneous. With the rise of strategic analysis and game theory, economics - at least in terms of methodology - can 
contribute to the study of the role of culture that goes beyond intuition and beyond what the other social sciences can give us. Not surprisingly, there is now a small literature rooted in game theory that does try to grapple with culture and social norms. ${ }^{1}$ But there is still a great distance to go.

As for policy, it turns out there is a lot that we can do when we are informed about the interconnections between social norms and economic performance. This is for two reasons. First, while I believe norms and culture are important determinants of economic well-being, I do not believe they are immutable. Cultures change, respond to education and advertising and, in fact, economics. I have elsewhere (Basu, 2004) discussed how in the 1950s Koreans were described as lacking in industry and having cultural mores that were doomed to economic failure, which is of course completely contrary to how we think about Koreans today. Now, while those descriptions may have been inspired, in part, by superciliousness, they also reflect how people's mores and cultures can change.

Stressing again the malleability of cultural mores and their connection to economic development, Geertz (1963, p.2) observes, "[It] has become more and more apparent that Tokugawa Japan, pre-1917 Russia, and the England of 1750 were not merely periods of quiet, unchanging stability before a sudden cataclysm of economic revolution, but rather periods of widespread intellectual and social ferment, in which crucial social relationships and cultural values were being altered in such a way as to allow an eventual large-scale reorganization of productive activities" (italics added).

All this suggests that we can try to eliminate or modify cultural traits that have harmful consequences on the economy and encourage the ones that aid efficiency and progress. And even though it is true that, at this stage, we do not fully understand what causes culture and social norms to change, the mere recognition that they do change and can potentially respond to policy is important and can help set up a useful research agenda exploring the link between various policies and what they do to our mores. Secondly, even when our norms and culture are fixed, knowing how they intertwine with economic variables, enables us to think of new policy interventions and assess more

\footnotetext{
${ }^{1}$ See, for instance, Kreps (1990), Sethi and Somanathan (1996), Young (1998), Basu (2000), Fehr and Fischbacher (2004), Rao and Walton (2004), Sen (2005).
} 
accurately the costs and benefits of interventions. I shall illustrate this with a formal model in section 3 , below.

\section{India}

There can be no denying that the Indian economy stands on the brink of big changes. Over the last decade or two it has grown at rates that were once unthinkable and, by contemporary global comparison, quite outstanding. India's current foreign exchange balance of $\$ 145$ billion makes it a country with the fifth highest foreign reserves in the world. This is a far cry from the early 1990s when her coffers were all but empty. It is this same fact that makes it surprising that Indian companies are becoming global players, with acquisitions occurring all around the world. In the software sector and, increasingly, in pharmaceuticals and steel India is becoming a global player.

Yet one has to be blind not to notice that much is wrong. India is home to the world's largest number of poor people - those who earn less than $\$ 1$ a day. Its global corporations may be known for their culture of efficiency and clean business, but it is a country of seething corruption, of small companies that double deal and cheat, of a bureaucracy that is grindingly slow and callous. To start a business in Singapore it takes 4 days to get the requisite bureaucratic clearances; in India it takes 88 days. The time it takes to resolve insolvency procedures for firms facing closure is 8 months in Singapore and 136 months in India. Many a CEO can well expect to exit the earth sooner than his firm is allowed to exit the industry.

Indian teacher absenteeism in government-run schools is reaching epidemic proportions and this problem is representative of much that is wrong with the bureaucracy. Several studies show that, when it comes to playing truant from school, Indian teachers are very good match for their students (PROBE, 1999 ; Rana, Rafique and Sengupta, 2002). A multi-country study in which researchers made surprise visits to government-run primary schools shows that in terms of teacher truancy, India is second only to Uganda and the defeat is by no means ignominious (Kremer et al, 2004). At any time, $25 \%$ of teachers are found missing from government-run schools in India; the figure for Uganda is $27 \%$. Kremer et al (2004) in fact found that only $45 \%$ of the teachers in 
India were actually teaching at the time of the surprise visits. It is not surprising that, while in terms of higher education India compares well even with industrialized nations many times richer than India, in terms of basic literacy India is at the bottom end of global charts, trailing behind several much poorer sub-Saharan African nations.

What should be done? For nearly forty years after India's independence a large number of Indian economists felt that large-scale planning, the public sector and government can solve all our problems. What is remarkable is that we are beginning to show the same kind of naiveté once again as a number of economists argue that leaving it all to the market and government making itself scarce can take care of all our problems.

The truth is that an economy is an extremely complex organism that requires plenty of abstract analysis, ample statistical information and a handsome dose of policy intuition. Markets, individual enterprise and incentives, the ability to write all kinds of contracts are crucial ingredients for an economy's success. But none of this can function unless government provides the requisite institutional structure (for one, the legal setting for effective and quick contract enforcement) and basic infrastructure. In addition government has to ensure that basic living standards are met and a safety net is provided for the poor and underprivileged. At the same time there is no point in crying hoarse about how our government and the politicians are worthless because government is, in turn, a product of the economy and society.

Fortunately, there is growing sophistication about the management of the economy and so there is hope that we will not keep swinging between all-government and markets-alone economics, as Indian economists have tended to do in the past. Where we have not shown sophistication - and this is true not just for India but for the profession of economics generally - is in realizing that much of economic behavior is embedded in social norms, culture and polity - as sociologists have long recognized ${ }^{2}$.

Let us consider the problem of teacher truancy in India. Why does it happen and how should one cure it? In answering such questions we have typically looked for economic variables. This can be very useful. We now know what effect sudden inspections have. We have some idea of the role of salaries on such behavior. Analysts

\footnotetext{
${ }^{2}$ See Weber (1905), Granovetter (1985), Granovetter and Soong (1983), Nee and Ingram (1998), Swedberg (2003, Chapter 9).
} 
have rightly stressed the role of incentives - both carrots and sticks - in creating greater work discipline among the teachers.

However, I believe that much of the problem is rooted in culture and social norms. Economists assume that, once we cite culture, we are basically planning to do a disappearing act in a welter of words and vague generalities. But that need not be so. It is possible to give rigorous shape to cultural explanations. I shall illustrate this with the example of the teacher truancy problem. But I believe similar cultural explanations are possible for many of the more vexing problems of the Indian economy, such as the sluggish and hindering bureaucracy, the problem of ubiquitous corruption, and also matters like workplace sloth.

\section{Model}

That there is more to teacher truancy or absenteeism from school than matters of economic incentives is suggested by the fact that there is an enormous variation in behavior patterns across states. The best state is Maharashtra with an absenteeism rate of $14.6 \%$ and the worst is Jharkhand with a rate of $41.9 \%$ (see Kremer et al, 2004). Other states are distributed between these two extremes, with, for instance, Kerala at $21.2 \%$, West Bengal 24.7\%, Punjab 34.4\% and Bihar 37\%, no doubt relieved that Jharkhand is not a part of it any more. Given that teacher salaries (in government-run schools) are standardized across the country and rules of reward and punishments are also fairly uniform across the states (and, I may add, close to zero), clearly a study of teacher truancy that bases itself solely on economic variables would be missing something important. I believe that the missing element here is the fact that human beings are social entities. They rely a lot on society's approval and try to stay away from behavior that meets with social stigma. It will be shown here that introducing a tiny element of this 'social' aspect can enormously enrich our understanding of the homo economicus. I can make no claims to originality in the model that follows. It draws on existing ideas and the only novelty is applying it to the problem of teacher truancy. Its importance derives from the fact that a similar reasoning underlies a lot of India's problems with bureaucracy and labor, in general. 
Consider an economy with a set, $N$, of teachers, where $N \equiv\{1,2, \ldots, t\}$. So there is a total of $t$ teachers. Let Rs. $w$ be the teacher's salary. Let Rs. $F$ be the fine a teacher has to pay if caught absenting himself from school without a valid reason. This is meant to be a summary measure of all the negative consequences that can occur because of truancy. The teacher may lose his job, not get an otherwise-expected raise in salary and so on. Instead of detailing such punishments I simply assume that there is a total fine of $F$. And let $p$ be the probability of being found out when a teacher plays truant. Hence $p F$ is the expected economic cost of truancy. Since all teachers face the same economic environment, there is no reason to put a teacher subscript to these variables.

Let $z(i)$ be the benefit that teacher $i$ gets by being truant from school. Thus $z(i)$ could be her income at her other job or the rupee-equivalent of the joys of sleep during the daytime. It will be assumed, without any loss of generality, that $j>i$ implies $z(j) \leq z(i)$.

Now, let me turn to the social variables. Assume that teachers, like all human beings, are moral creatures and get satisfaction from knowing that their teaching confers benefit to society. Let the value of this be $v$. In reality, the valuation of this benefit will vary from person to person and should be written as $v(i)$. But for algebraic simplicity, I will assume that this is constant across teachers.

Finally, a teacher who plays truant suffers social criticism. Let $s$ denote this 'stigma' cost of truancy. Clearly there is a cultural element in this. If lots of teachers are truant, this becomes acceptable behavior; and so in such a society, $s$ will be small. On the other hand, if very few teachers are truant, $s$ will be larger. So if $n$ is the number of teachers, who play truant, we can think of the stigma cost being a function of this. It could be written as $s(n)$, where $s^{\prime}(n)<0$. This feature of stigma was used by Lindbeck, Nyberg and Weibull (1999) to understand variations in Swedish unemployment ${ }^{3}$.

Let us now consider a teacher $i \in N$ and see how he will decide whether or not to be truant. Suppose that he expects that $n$ teachers will be truant. So, if $i$ is a 'diligent teacher'--let this be our term for someone who does not give in to truancy--, then his benefit is $w+v$. If he is truant, his benefit is $w+z(i)-p F-s(n)$.

Hence, $i$ will choose to be truant if and only if 


$$
w+z(i)-p F-s(n) \geq w+v
$$

or

$$
z(i) \geq s(n)+v+p F
$$

By using (2) for different $i$ 's we can in fact find out how many teachers will choose to play truant. This can be seen clearly using a diagram. Let the horizontal axis in Figure 1 represent teachers, from 1 to $t$. The figure shows the graph of the $z(i)$-function. Now, suppose $n$ is the believed or expected level of teacher truancy. Given $n$, calculate $s(n)+v+p F$ and draw a horizontal line in the same figure where the line occurs at a height of this value. This line is shown by AB. What we can assume is that OA in the figure is equal to $s(n)+v+p F$.

It is obvious that every teacher, $i$, to the left of $m$ will be truant. This follows from (2). Hence, the number of teachers who will play truant is $m$. Mathematically, $m$ is that element of $N$ such that

$$
z(m)=s(n)+v+p F
$$

Equation (3) defines $m$ implicitly. It says that, if $n$ teachers are expected to be truant, then $m$ teachers, where $m$ is given by (3), will in fact be truant.

\section{Figure 1.}

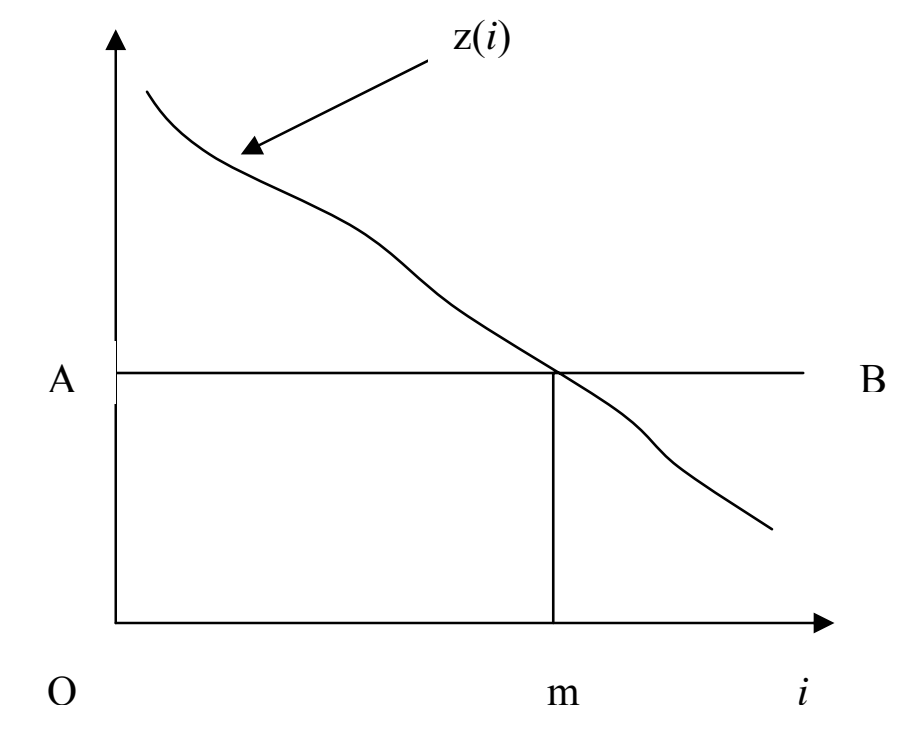

\footnotetext{
${ }^{3}$ See, also, Besley and Coate (1992), Lopez-Calva (2003).
} 
Clearly, if $m \neq n$, then this cannot be an equilibrium, because people will gradually realize that their initial expectation of the incidence of truancy was wrong. As they adjust their beliefs, their behavior will change. We will have an equilibrium when we find an expectation of truancy that gets corroborated by the behavior that is generated by that expectation.

In order to say this a bit more formally, let me rewrite equation 3 differently, where $m$ is explicitly a function of $n$. This may be written as

$$
m=\phi(n, v, p F)
$$

In other words, $\phi$ is defined such that, for all $n, v, p F, z(\phi(n, v, p F))=s(n)+v+p F$. Since, $\mathrm{s}^{\prime}(\mathrm{n})<0$, and $z^{\prime}(m)<0$, it is obvious that

$$
\frac{\partial \phi(n, v, p F)}{\partial n}>0
$$

Hence as $n$ increases, $\phi$ will increase.

Now, we can define an equilibrium. Given $v, p F$, we shall say that $n^{*}$ is an equilibrium level of teacher truancy if and only if

$$
n^{*}=\phi\left(n^{*}, v, p F\right) \text {. }
$$

Figure 2 illustrates an equilibrium. In that figure, I have drawn the graph of a possible $\phi$-function. Since this is upward-sloping (in $n$ ) and is obviously bounded from above, the case illustrated is a plausible one. In this economy, there are three equilibria, with teacher truancy levels in equilibrium being at $n^{1}, n^{2}$ and $n^{3}$. 
Figure 2.

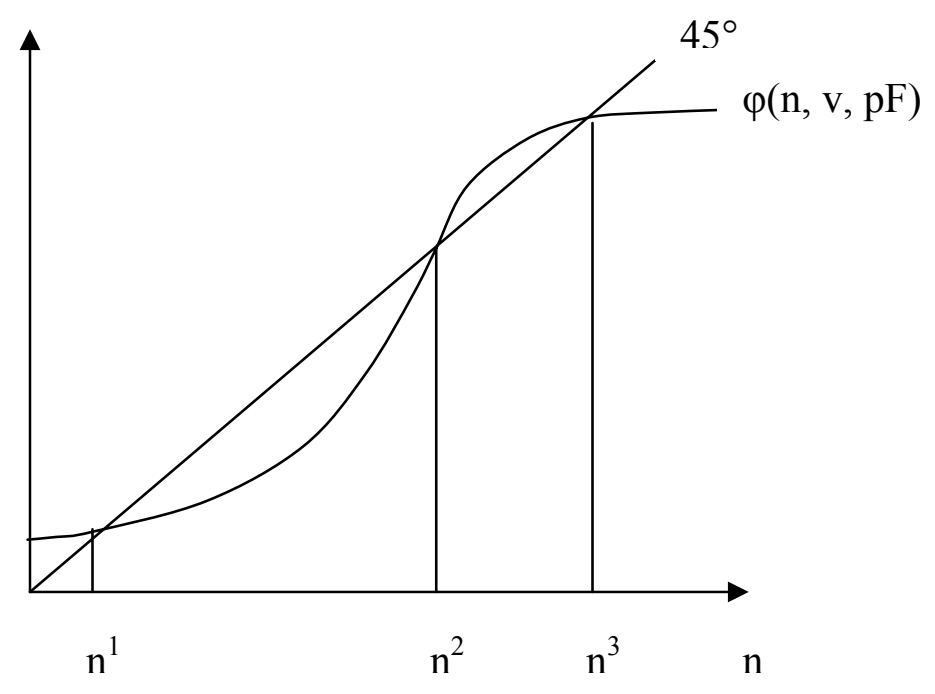

This shows that an economy can have multiple equilibria. Two economies that are identical ex ante with identical economic environments (that is, with $w, p$ and $F$ identical) can exhibit very different kinds of behavior ex post, meaning after the equilibrium is established.

We can now see why Jharkhand and Maharashtra can have such different levels of teacher absenteeism, despite the standardization of economic incentives across the nation. It is simply that the two places have developed different cultures of what constitutes acceptable behavior. But acceding significance to culture does not mean that the role of economic policy becomes any less significant. But it does mean that economic variables may work differently than what standard textbooks tell us. And this is indeed the value of this kind of analysis, since it takes us closer to how people behave in reality.

First of all, economists attach too little importance to the role of direct social education and other attempts to alter social norms. It is known that people can learn to be social. This can be in the sense of people learning to use a sense of fairness and justice to select among multiple equilibria, as modeled by Myerson (2004); and this has deep implications for understanding institutions of justice. But it can also be so in the sense of altering our preferences. Human beings can, for instance, be taught to be altruistic and 
they can be persuaded to be more trustworthy. Countries have been known to witness changes in the habits of its citizenry, such as the habit of littering the streets or smoking in public or unmentionables in public. It is true that the process through which these changes occur and the stimulus that causes these changes are not adequately understood. But we know, in principle, that it is possible to change these norms and preferences. In the present context it means, for instance, that it is possible to raise the value of $v$ or raise the stigma-function upwards, which would, in turn, encourage teachers to do their work more diligently.

But this is not the line that I shall pursue here. What I will show here is that, even if our preferences and values remain unaltered, behavior can be changed by the use of standard economic interventions; but these interventions can be made extra effective by using the leverage of their connection with the stigma variable.

Let me make a small assumption. If the $\phi$-function moves up and down a little, let us assume that the selected equilibrium remains in the vicinity of the original equilibrium, that is, it does not 'jump' to another far away equilibrium. Now suppose an economy is at $n^{3}$ in Figure 2. It is easy to check if the economic punishment for truancy is raised, that is, $p F$ is raised, then the graph of the $\phi$-function will move down. Hence, equilibrium truancy will go down by a small amount.

In traditional analysis, without social variables entering the picture, we would rightly suppose that if we wanted truancy to drop a lot, that is, to go to $n^{1}$, we would need a large increase in $p F$, roughly proportionately to what was needed for the small change. But notice what happens in this model. As $p F$ is raised steadily, suddenly the hightruancy equilibrium vanishes and the only existing equilibrium will be close to $n^{1}$, in fact, to the left of $n^{1}$ (since the graph of the $\phi$-function would have shifted) ${ }^{4}$.

Suppose we hold the economy there for a while, that is, keep $p F$ raised as much as needed to make the high-truancy equilibrium disappear. After a while, if we set $p F$ back to where it originally was, so that the $\phi$-function returns to where it is in Figure 2, the economy will now remain at $n^{1}$. In other words, no permanent policy changes are needed to alter economic behavior. A temporary policy can achieve permanent changes in

\footnotetext{
${ }^{4}$ This is the same kind of argument that was used in the celebrated paper by Schelling (1972) on segregated housing.
} 
behavior. This is, of course, a consequence of there being a multiplicity of equilibria ${ }^{5}$, which, in turn, occurs in this model because of the role played by social stigma.

\section{Conclusion}

The model was meant to be an illustration of the possibilities that open up once we make room for sociological variables. It can be extended in different directions. If, for instance, the size of stigma to person $i, s_{i}$, depends not just on the total number of people in the economy who choose to be truant, but to the number of people who choose to be truant in $i$ 's community, the results would change ${ }^{6}$. This could mean the emergence of community level differences. One group can exhibit a significantly higher level of truancy than another. This, in turn, can create feedbacks whereby persons of one community are favored over another for jobs and other responsibilities. ${ }^{7}$ In such a model the community-based preferences need not be caused by any ex ante racism, but is a concomitant of equilibrium, an ex post feature of the equilibrium. But, of course, it can be as repressive as innate racism.

Cultural models can shed light on other areas of concern to India's policy makers, such as bureaucratic behavior, corruption and labor market inefficiencies. In trying to improve labor market performance and the welfare of the workers themselves, we usually recommend changes in India's labor laws and regulation (Papola, 1994; Basu, 2006). But a lot of what happens in the labor market happens with no reference to the law. This happens both because so much of the labor market in developing countries lies outside the formal sector (see Ghose, 2003, pp. 45-7) and because we often collectively overlook the law ${ }^{8}$. Hence, outcomes are much more dependent on norms and mores of the labor market than economists have typically acknowledged (see Singh, 2000, for discussion). And, therefore, if we want to improve labor market functioning, we need to pay more attention on how to influences these norms and the culture of the workplace.

\footnotetext{
${ }^{5}$ A similar policy problem, where a temporary intervention could have permanent effect was studied in the context of child labor by Basu and Van (1998).

6 'Community' here can refer to a racial group, a caste category, $i$ 's co-religionists and so on.

${ }^{7}$ Hence, the model can be taken the route of membership-based theories of economic behavior (see, for example, Banerjee and Munshi 2004; Durlauf, 2001; Basu, Genicot and Stiglitz, 2003).
} 
Moving away further from the formal model, one can speculate about what influences our moral and cultural preferences. For instance, it is known that the aesthetics of one's environment matters in determining how one behaves. People, who live in graffiti-scarred, bottle-littered neighborhoods, develop a sense of failure and resignation; and so cleaning up an area can be a first step in controlling gang violence, for instance. Indian bureaucratic offices are often maintained poorly, with litter and the cubism of discarded furniture piled high. It is easy to feel resigned to lower standards in such an environment and not strive to realize one's better self.

Economists, being professionally trained to looking at prices and resources, incomes and wages, and pecuniary incentives, tend to dismiss cultural explanations as vague and useless. But if we take serious stock of the success we have had (very little) in controlling corruption, absenteeism at work and bureaucratic red tape, we will realize that culture may at least be worth a try.

\footnotetext{
${ }^{8}$ Interestingly, the informal sector can actually expand during a crisis (see Islam et al, 2001, in the context of Indonesia), thereby making greater room for fugitives from the labor law.
} 


\section{References}

Banerjee, A. and Munshi, K. (2004), 'How Efficiently is Capital Allocated? Evidence from the Knitted Garment Industry in Tirupur', Review of Economic Studies, vol. 71 .

Basu, K. (2000), Prelude to Political Economy: A Study of the Social and Political Foundations of Economics, New York and Oxford: Oxford University Press.

Basu, K. (2004), 'The Indian Economy: Up to 1991 and Since,' in K. Basu (ed.), India's Emerging Economy: Problems and Prospects in the 1990s and Beyond, Cambridge, MA: MIT Press.

Basu, K. (2006), 'Labor Laws and Labor Welfare in the Context of the Indian Experience,' in A. de Janvry and R. Kanbur (eds.), Poverty, Inequality and Development: Essays in Honor of Erik Thorbecke, New York: Springer.

Basu, K., Genicot, G. and Stiglitz, J. (2003), 'Minimum Wage Laws and Unemployment Benefits when Labor Supply is a Household Decision,' in K. Basu, P.B. Nayak and R. Ray (eds.), Markets and Governments, New Delhi: Oxford University Press.

Basu, K. and Van, P.H. (1998), 'The Economics of Child Labor', American Economic Review, vol. 88

Besley, T. and Coate, S. (1992), 'Understanding Welfare Stigma: Tax payer Resentment and Statistical Discrimination,' Journal of Public Economics, vol. 48.

Durlauf, S. (2001), 'The Membership Theory of Poverty: The Role of Group Affiliations in Determining Socioeconomic Outcomes', in S. Danziger and R. Haveman (eds.), Understanding Poverty in America, Cambridge, MA: Harvard University Press.

Fehr, E. and Fischbacher, U. (2004), 'Social Norms and Human Capital,' TRENDS in Cognitive Sciences, vol. 8, 185-90.

Fukuyama, F. (1995), Trust: The Social Virtues and the Creation of Prosperity, New York: Free Press.

Geertz, C. (1963), Peddlers and Princes, Chicago: Chicago University Press. Ghose, A. K. (2003), Jobs and Incomes in a Globalizing World, Geneva: ILO. 
Granovetter, M. (1985), 'Economic Action and Social Structure: The Problem of Embeddedness,' American Journal of Sociology, vol. 91, 481-510.

Granovetter, M. and Soong, R. (1983), 'Threshold Models of Diffusion and Collective Behavior,' Journal of Mathematical Sociology, vol. 9, 165-79.

Islam, R. et al (2001), 'The Economic Crisis: Labor Market Challenges and Policies in Indonesia,' in Betcherman, G. and Islam, R. (eds.), East Asian Labor Markets and the Economic Crisis, Washington: World Bank, and Geneva: ILO.

Kremer, M., Muralidharan, K., Chaudhury, N., Hammer, J. and Halsey Rogers, F. (2004), 'Teacher Absence in India: A Snapshot,' Journal of European Economic Association, forthcoming.

Kreps, D. (1990), 'Corporate Culture and Economic Theory,' in J. Alt and K. Shepsle (eds.), Perspectives on Positive Political Economy, Cambridge: Cambridge University Press.

Lindbeck, A., Nyberg, S. and Weibull. J. (1999), 'Social Norms and Economic Incentives in the Welfare State,' Quarterly Journal of Economics, vol. 114, 1-35.

Lopez-Calva, L.-F. (2003), 'Social Norms, Coordination and Policy Issues in the Fight Against Child Labor,' in K. Basu, H. Horn, L. Romain and J. Shapiro (eds.), International Labor Standards, Oxford: Blackwell Publishing.

Myerson, R. (2004), 'Justice, Institutions and Multiple Equilibria', Chicago Journal of International Law, vol. 5, 91-107.

Nee, V. and Ingram, P. (1998), 'Embeddedness and Beyond: Institutions, Exchange and Social Structure,' in M. Brinton and V. Nee (eds.), The New Institutionalism in Sociology, New York; Russell Sage Foundation.

Papola, T. S. (1994), 'Structural Adjustment, Labor Market Flexibility and Employment,' Indian Journal of Labour Economics, vol. 37.

PROBE (1999), Public Report on Basic Education in India, New Delhi: Oxford University Press.

Rana, K., Rafique, A., and Sengupta, A. (2002), The Pratichi Education Report: The Delivery of Primary Education, New Delhi: The Pratichi India Trust.

Rao, V. and Walton, M. (2004), Culture and Public Action, Stanford: Stanford University Press. 
Schelling, T. (1972), 'The Process of Residential Segregation: Neighborhood Tipping,' in A. Pascal (ed.), Racial Discrimination in Economic Life, Lexington MA: Lexington Books.

Sen, A. (2005), The Argumentative Indian: Writings on Indian History, Culture and Identity, New York: Farrar, Straus and Giroux.

Sethi, R. and Somanathan, E. (1996), 'The Evolution of Social Norms in Common Property Resource Use,' American Economic Review, vol. 86, 766-88.

Singh, J. (2000), Some Aspects of Industrial and labour Markets in India; Perspectives from law and Economics, PhD thesis, Delhi School of Economics, Delhi University.

Swedberg, R. (2003), Principles of Economic Sociology, Princeton: Princeton University Press.

Weber, M. (1905), The Protestant Ethic and the Spirit of Capitalism, New York: Scribner's [Published 1958].

Young, P. (1998), Individual Strategy and Social Structure, Princeton: Princeton University Press. 